

\section{DISClammer}

Portions of this document may be illegible in electronic image products. Images are produced from the best available original document. 


\title{
OXYGEN TRANSPORT BY OXYGEN POTENTIAL GRADIENT IN DENSE CERAMIC OXIDE MEMBRANES
}

\author{
P. S. Maiya, U. Balachandran, J. T. Dusek, and R. L. Mieville \\ Energy Technology Division \\ Argonne National Laboratory \\ Argonne, Illinois 60439-4838 \\ and \\ M. S. Kleefisch, C. A. Udovich \\ Amoco Exploration/Production \\ Naperville, Illinois 60566
}

\begin{abstract}
Numerous studies have been conducted in recent years on the partial oxidation of methane to synthesis gas (syngas: $\mathrm{CO}+\mathrm{H}_{2}$ ) with air as the oxidant. In partial oxidation, a mixed-oxide ceramic membrane selectively transports oxygen from the air; this transport is driven by the oxygen potential gradient. Of the several ceramic materials we have tested, a mixed oxide based on the $\mathrm{Sr}-\mathrm{Fe}-\mathrm{Co}-\mathrm{O}$ system has been found to be very attractive. Extensive oxygen permeability data have been obtained for this material in methane conversion experiments carried out in a reactor. The data have been analyzed by a transport equation based on the phenomenological theory of diffusion under oxygen potential gradients. Thermodynamic calculations were used to estimate the driving force for the transport of oxygen ions. The results show that the transport equation deduced from the literature describes the permeability data reasonably well and can be used to determine the diffusion coefficients and the associated activation energy of oxygen ions in the ceramic membrane material.
\end{abstract}

\section{INTRODUCTION}

Upgrading of natural gas, which contains mostly methane, to value-added products requires an intermediate step that involves the manufacture of syngas $\left(\mathrm{CO}+\mathrm{H}_{2}\right)$. Apart from technical considerations, production of syngas constitutes an important step because $\approx 40-50 \%$ of the process capital cost arises from the syngas manufacturing plant itself. The most commonly used process used to convert methane to syngas is steam reforming, ${ }^{1}$ but the reaction of methane with steam is strongly endothermic, has poor selectivity for carbon monoxide, and demonstrates other characteristics that make this process less attractive from a process-efficiency standpoint. Therefore, recent efforts have focused on partial direct oxidation of methane with air as the oxidant. This reaction is exothermic and exhibits better selectivity, and thus yields a more desirable $\mathrm{H}_{2} / \mathrm{CO}$ ratio.

In a joint R\&D effort between Amoco Exploration/Production and Argonne National Laboratory, we have shown ${ }^{2}$ that oxygen from air can be transported through a dense ceramic membrane tube (extruded from a ceramic oxide based on the $\mathrm{Sr}-\mathrm{Fe}-\mathrm{Co}-\mathrm{O}$ system) 
that is subjected to an oxygen potential gradient at an elevated temperature. The process requires neither cryogenic separation of undesirable nitrogen nor an oxygen plant, which adds significantly to the capital cost of the overall process. Several investigators ${ }^{3-7}$ have reported ceramic-membrane reactor concepts in which oxygen from air migrates through a dense membrane by diffusion, without the use of an externally applied potential. These investigators have also reported that high oxygen flux is achieved as a result of high diffusivity of oxygen through the membrane. For use in commercial applications, the membrane should have sufficient chemical stability and mechanical integrity at elevated temperatures.

The simple process concept is shown in Fig. 1, a schematic representation of oxygen transport through a mixed-conducting $\mathrm{I}_{\mathrm{I}}$ ceramic membrane. Oxygen ions are driven from the higher-oxygen-pressure air side $\mathrm{pO}_{2}$ to the lower-oxygen-pressure side of the membrane $\mathrm{pO}_{2}$, whereas electrons are driven in the opposite direction. Oxygen transported from the air side through the membrane reacts with methane on the lowoxygen-pressure side of the membrane to form syngas. The flow of air and $\mathrm{Ar}+\mathrm{CH}_{4}$ in the tube can be reversed, i.e., air can flow inside the tube and $\mathrm{Ar}+\mathrm{CH}_{4}$ can be on the outside. Syngas is then converted to other value-added products such as methanol and liquid hydrocarbons.

Of several mixed-conducting ceramics (mostly belonging to the perovskite family) that we investigated, a new material based on the $\mathrm{Sr}-\mathrm{Fe}-\mathrm{Co}-\mathrm{O}$ system $\left(\mathrm{SrFeCo} .5 \mathrm{O}_{\mathrm{x}}\right.$, nonperovskite) has emerged as a potentially attractive candidate material; 8 it is designated SFC-2. Several plastic-extruded and sintered, dense, thin-walled tubes were successfully tested in methane-conversion reactors for $>1000 \mathrm{~h}$. This candidate material withstood the hostile experimental conditions much longer than many of the materials we have tested. In addition, the high oxygen flux produced by the oxygen potential gradient makes the ceramic membrane suitable for commercial applications. Extensive results on the oxygen permeability of SFC-2 have been obtained at different temperatures and over a range of flow rates and feed gas compositions. Limited experiments on tubes with various wall thicknesses suggest that oxygen transport through the membrane is not controlled by surface reactions because permeation increased with a decrease in thickness. In this report, we have assumed that oxygen ion movement is controlled by diffusion and not by surface-controlled reactions.

It is not convenient to use some of the existing models 9,10 of oxygen transport to describe our data. Therefore, to deduce a simple oxygen transport equation, we have used the phenomenological theory of diffusion in mixed conducting materials, $11-14$ in conjunction with relevant fundamental relationships generally used to describe the transport of charged particles. This oxygen transport model permits us to determine diffusion coefficients and activation energy from oxygen permeability data.

\section{OXYGEN TRANSPORT IN AN OXYGEN POTENTIAL GRADIENT}

The basic premise of the transport of any charged particle in a solid is electrochemical potential. In oxides that contain charged particles (electrons and oxygen ions), the electrochemical potential of particles of type $i, \eta_{i}$ (either electrons or oxygen ions), is defined as 


$$
\eta_{i}=\mu_{i}+z_{i} F \varphi
$$

where $\mu_{\mathrm{i}}$ is the chemical potential, $z_{\mathrm{i}}$ is the valence of the charged species, $\mathrm{F}$ is the Faraday constant, and $\phi$ is the local electrical potential. The partial current density of charged species $i$ is formally represented by 12,13

$$
I_{i}=-\frac{\sigma_{i}}{z_{i} F} \frac{d \eta_{i}}{d x}
$$

where $\sigma_{\mathrm{i}}$ is the electrical conductivity. Application of Eq. 2 to oxygen ions and electrons leads to the partial current density of oxygen ions given by 13

$$
\mathrm{I}_{\mathrm{O}_{2^{-}}}=-\frac{\sigma_{\mathrm{O}_{2^{-}}}}{\mathrm{z}_{\mathrm{O}_{2^{-}}} \mathrm{F}}\left(\frac{\mathrm{d} \eta_{\mathrm{i}}}{\mathrm{dx}}\right)=\frac{\sigma_{\mathrm{O}_{2^{-}}}}{2 \mathrm{~F}}\left(\frac{\mathrm{d} \eta_{\mathrm{i}}}{\mathrm{dx}}\right)
$$

and, similarly, the partial current density of electrons is represented by

$$
\mathrm{I}_{\mathrm{e}^{-}}=\frac{\sigma_{\mathrm{e}^{-}}}{\mathrm{F}}\left(\frac{\mathrm{d} \eta_{\mathrm{i}}}{\mathrm{dx}}\right)
$$

Ramanarayanan et al. 13 applied Eqs. 3 and 4 to a system where oxygen gas, electrons, and oxygen tons are in equilibrium and showed that the current density of oxygen ions is represented by

$$
\mathrm{I}_{\mathrm{O}^{2-}}=\frac{\sigma_{\mathrm{O}^{2-}}}{4 \mathrm{~F}}\left(1-\frac{\sigma_{\mathrm{O}^{2-}}}{\sigma_{\mathrm{e}^{-}}+\sigma_{\mathrm{O}^{2-}}}\right) \frac{\mathrm{d} \mu_{\mathrm{O}_{2}}}{\mathrm{dx}}
$$

where the partial current density is proportional to the chemical potential gradient, $\frac{d \mu_{\mathrm{O}_{2}}}{\mathrm{dx}}$. Simplification of Eq. 5 yields

$$
I_{\mathrm{O}^{2-}}=\frac{\sigma_{\mathrm{O}^{2-}}}{4 \mathrm{~F}}\left(\frac{1}{1+\frac{\sigma_{\mathrm{O}^{2-}}}{\sigma_{\mathrm{e}^{-}}}}\right) \frac{\mathrm{d} \mu_{\mathrm{O}_{2}}}{\mathrm{dx}} .
$$

The electrical conductivity and diffusion coefficient of charged species $i$ are related by the Nernst-Einstein equation

$$
\sigma_{\mathrm{i}}=\frac{D_{\mathrm{i}} c_{\mathrm{i}}}{\mathrm{RT}}\left(\mathrm{z}_{\mathrm{i}} \mathrm{F}\right)^{2} \text {. }
$$


where $D_{i}$ is the diffusion coefficient, $c_{i}$ is the concentration of the diffusing species, $R$ is the gas constant, $T$ is temperature in Kelvins, and $z_{i}=2$ for oxygen ions. Substituing the Nernst-Einstein equation in Eq. 6 and converting the oxygen current density to oxygen ion flux. we obtain

$$
\mathrm{J}_{\mathrm{O}_{2-}}=\frac{\mathrm{D}_{\mathrm{O}^{2-}} \mathrm{c}_{\mathrm{O}^{2-}}}{2 \mathrm{RT}}\left(\frac{1}{1+\frac{\sigma_{\mathrm{O}^{2-}}}{\sigma_{\mathrm{e}^{-}}}}\right) \frac{\mathrm{d} \mu_{\mathrm{O}_{2}}}{\mathrm{dx}}
$$

For a thin-walled ceramic tube, when oxygen ion migration occurs in an oxygen pressure gradient, Eq. 8 can be further simplified to

$$
\mathrm{J}_{\mathrm{O}^{2-}}=\frac{1}{2} \frac{\mathrm{D}_{\mathrm{eff}} \mathrm{c}_{\mathrm{o}^{2-}}}{\mathrm{L}} \ln \left(\frac{\mathrm{pO}_{2}^{\mathrm{I}}}{\mathrm{pO}}\right) \text {, }
$$

where $L$ is the thickness of the tube and $D_{\text {eff }}$ is the effective diffusion coefficient of oxygen ions, which is defined as ${ }^{15}$

$$
\mathrm{D}_{\mathrm{eff}}=\mathrm{D}_{\mathrm{O}^{2-}}\left(\frac{1}{1+\frac{\sigma_{\mathrm{O}^{2-}}}{\sigma_{\mathrm{e}^{-}}}}\right)
$$

It can easily be seen that, in mixed-oxide conductors, when electronic conductivity is appreciable when compared with ionic conductivity, the local electric field is small. Thus, the effective diffusion coefficient is closer to the diffusion coefficient of oxygen ions. If electronic conductivity is lower than ionic conductivity, the local electric field is large and oxygen ion migration is impeded by this field. For SFC-2, the transference number for oxygen ions in air at $800^{\circ} \mathrm{C}$ is $\approx 0.41$ so that the difference between $\mathrm{D}_{\text {eff }}$ and $\mathrm{D}_{\mathrm{O}^{2-}}$ is approximately within a factor of 2.16 Therefore, although transport Eq. 8 contains electronic and ionic conductivity, the values of the conductivity terms are not required and the phenomenological approach enables the determination of the effective diffusion coefficient (approximate diffusivity of oxygen ions in SFC-2) and its temperature dependence from the oxygen permeability data obtained in a methane-conversion reactor, as described below.

\section{EXPERIMENTAL RESULTS}

As mentioned earlier, extensive oxygen permeability data have been obtained for a dense ceramic tube extruded from SFC-2. Density of the sintered tube is $>92 \%$ of theoretical. The outside diameter is $7 \mathrm{~mm}$ and the wall thickness is $0.75 \mathrm{~mm}$. A quartz reactor configuration (Fig. 2) supports the SFC-2 ceramic-membrane tube with hot Pyrex 
seals. This design allows the SFC-2 tube to be in an isothermal environment so permeability data can be obtained at a specified temperature. To facilitate reactions and equilibration of gases in the reactor, $2.5 \mathrm{~g}$ of catalyst are loaded adjacent to the tube. A gold wire mesh is wrapped around the tube to prevent a solid-state reaction between the reforming catalyst and the SFC-2 tube. Total exposed surface area of the membrane is 4.4 $\mathrm{cm}^{2}$. The reactor system is completely automated for sampling and analyzing the effluent gases. Samples were injected every $8 \mathrm{~h}$ into a Hewlett-Packard 5890 gas chromatograph.

The reactor was mounted in the unit and heated to $1000^{\circ} \mathrm{C}$ without gas flows on either side of the membrane. This step was necessary to ensure leak-free Pyrex seals. Once the springs compressed the plunger into the receiver, thereby forcing the Pyrex into a gastight seal, the furnace could be cooled to the desired operating temperature. However, the operating temperature must not be $<750^{\circ} \mathrm{C}$ because the Pyrex will start to delaminate from the SFC-2 and begin to leak. Control thermocouples were positioned at the top, middle, and bottom of the ceramic tube. Once the temperature was stabilized, air was introduced into the reactor by passing it at $\approx 1.2 \mathrm{~L} / \mathrm{min}$ (Fig. 2). The shell side of the membrane was then purged with helium. Leaks were detected by monitoring the helium for nitrogen. Fuel gas ( $80 \%$ methane and $20 \%$ argon) was introduced at a flow rate of $10 \mathrm{~cm}^{3} / \mathrm{min}$. The argon in the fuel gas was used as an internal standard. A large exotherm was observed when the fuel contacted the membrane; at that time, fuel flow is adjusted.

Syngas is produced according to the following reaction:

$$
\mathrm{CH}_{4}+\frac{1}{2} \mathrm{O}_{2}=2 \mathrm{H}_{2}+\mathrm{CO}
$$

Reaction products consisted predominantly of syngas, argon (used as the internal standard), carbon dioxide and unreacted methane. Data were collected $24 \mathrm{~min}$ from the start of the experimental run, and samples are taken every $8 \mathrm{~h}$ thereafter. The set-point temperature was changed to obtain different temperatures and the flow rate was adjusted to maintain conversions of $>80 \%$ except near the end of the experimental run. The carbon monoxide selectivity (defined as the mole $\%$ of carbon monoxide divided by the total amount of carbon, multiplied by 100 ) remained near $100 \%$ throughout the entire run. While the $\mathrm{H}_{2} / \mathrm{CO}$ product ratio ranged from 1.7 to 2.0 , carbon balance varied by only $5 \%$ over a period of $1000 \mathrm{~h}$. The data included in the analysis were obtained under steady-state conditions.

\section{ANALYSIS OF RESULTS}

To estimate oxygen ion diffusivity, equilibrium oxygen pressure on the reduction side of membrane is required. The $\mathrm{pO}_{2}$ on the methane side is calculated from the gas composition with SOLGAS, 17,18 a computer program for determining the equilibrium phases in a system based on minimization of free energy. It is assumed that all of the oxygen transported through the membrane is consumed in the methane conversion to syngas. These are thermodynamic equilibrium calculations, but they are adequate for our purposes. For example, the results of one experiment at $1165 \mathrm{~K}$, normalized to the starting amount of argon, indicate that the total amounts of carbon and hydrogen were $\approx 101.3$ and $99.7 \%$, respectively, of the amount in the feed gas. These results are within the experimental error. 
In Table I, results of the SOLGAS computations are compared to experimental results. The experimental results were normalized to exactly 21.24 moles of argon, which was the input quantity. The computed $\mathrm{pO}_{2}$ was $3.55 \times 10^{-22}$ atm, which yields an oxygen potential of $-478.2 \mathrm{~kJ} / \mathrm{mole}$. As can be seen from Table I, agreement between the computed equilibrium composition and the experimental results is good. Thus, the driving force for oxygen transport can be calculated (oxygen pressure on the air side is $\approx 0.21 \mathrm{~atm}$ ) and used in the above model. The concentration of oxygen ions in the SFC-2 lattice is estimated from its density ( $5.1478 \mathrm{~g} \mathrm{~cm}^{-3}$ ) and the molecular formula and is found to be equal to 0.0349 moles $/ \mathrm{cm}^{3}$. It should be noted that diffusion coefficient is expressed in $\mathrm{cm}^{2} / \mathrm{s}$. The units of oxygen ion flux $\mathrm{J}_{\mathrm{O}^{2-}}$ in Eq. 9 can be arbitrarily chosen (for example, moles $/ \mathrm{cm}^{2} / \mathrm{s}$ or $\mathrm{cm}^{3} / \mathrm{cm}^{2} / \mathrm{s}$ ), but the units of oxygen ion concentration must then correspond.

The SOLGAS calculations showed that the driving force is weakly dependent on temperature (Fig. 3) and is assumed to be approximately constant. The temperature dependence of the diffusion coefficient (Fig. 4) is given by

$$
\mathrm{D}_{\mathrm{eff}}=4.37 \exp \left(\frac{-156,000}{\mathrm{RT}}\right) \mathrm{cm}^{2} / \mathrm{s}
$$

where the activation energy for diffusion is $156 \mathrm{~kJ} /$ mole, $\mathrm{R}$ is the gas constant $(8.3143$ $\mathrm{J} \mathrm{K}^{-1}$ mole $^{-1}$ ), and $\mathrm{T}$ is the temperature in Kelvins. The activation energy determined for SFC-2 is within the range of values reported for lanthanum-based nonstoichiometric perovskite-structure oxides $\left(60-350 \mathrm{~kJ}\right.$ mole $\left.^{-1}\right)$ from permeability experiments. ${ }^{19}$ It is also within the range of two values, namely 210 and $125 \mathrm{~kJ}$ mole ${ }^{-1}$ reported for $\mathrm{SrCo}_{.8} \mathrm{Fe}_{0.2} \mathrm{O}_{\mathrm{x}}$ and $\mathrm{SrCo}_{0.2} \mathrm{Fe}_{0.8} \mathrm{O}_{\mathrm{x}}$, respectively. 20 With transport Eq. 9 and calculated oxygen partial pressure on the methane side, it is observed that the estimated and experimentally observed oxygen flux is within $25 \%$. Thus, within the range of variables, the experimentally observed oxygen permeability data can be described reasonably well by transport Eq. 9 .

Analysis of the oxygen permeability data we have described in this report is expected to be useful in modeling studies that estimate total oxygen consumed, and hence the total amount of syngas produced, for a given configuration of the reactor as functions of temperature and wall thickness. For example, we can consider the syngas production rate from a flat multichannel strip and a tube extruded from SFC-2 and sintered, in particular, a flat, 25.4-cm-long, $2.21-\mathrm{cm}$-wide multichannel strip with a $0.02-\mathrm{cm}$-thick wall and a tube (outside diameter $=0.67 \mathrm{~cm}$ and wall thickness $=0.08 \mathrm{~cm}$ ). Noting that each mole of oxygen consumed in the methane conversion produces six times the amount of syngas in accordance with Eq. 11, we can calculate the production rate of syngas as a function of temperature for the two conceptual reactor configurations; results are shown in Fig. 5 . We emphasize that in these estimates, it is assumed that oxygen flux is inversely proportional to wall thickness. If the increase in oxygen flux as wall thickness is reduced is greater than that indicated by the relationship between the two quantities in the oxygen transport equation, the estimate of syngas production rate for the flat multichannel strip becomes conservative. Controlled experiments will be performed to gain an understanding of the effects of thickness and driving forces on oxygen permeability. 


\section{SUMMARY AND CONCLUSIONS}

To describe the oxygen permeability data obtained for a ceramic tube subjected to oxygen pressure gradients, we have used the phenomenological theory of diffusion in mixed-conducting materials, where the basic premise of transport is electrochemical potential. It is observed that the experimental results can be described reasonably well by the following transport equation:

$$
\mathrm{J}_{\mathrm{O}^{2-}}=\frac{1}{2} \frac{\mathrm{D}_{\mathrm{eff}}^{\mathrm{c}} \mathrm{o}^{2-}}{\mathrm{L}} \ln \left(\frac{\mathrm{p \stackrel { \textrm {O } } { 2 }}_{\mathrm{II}}^{\mathrm{II}}}{\mathrm{p} \mathrm{O}_{2}}\right) \text {. }
$$

where $J_{O^{2-}}$ is the oxygen lon flux, $L$ is the wall thickness, $c_{O^{2-}}$ is the concentration of oxygen ions, $\mathrm{pO}_{2}$ and $\mathrm{pO}_{2}$ are the partial pressures on the air and methane side, respectively, and $D_{\text {eff }}$ is the effective diffusion coefficient of oxygen ions and contains both electronic and ionic conductivity terms. However, for the material under investigation, $\mathrm{D}_{\text {eff }} \approx \mathrm{D}_{\mathrm{O}}$ 2- and thus the diffusion coefficients and the associated activation energy are determined. To estimate oxygen ion diffusivity, equilibrium oxygen pressure on the reduction side of membrane is required. This oxygen pressure is calculated from gas composition with the computer code SOLGAS. The agreement between the computed equilbrium composition and the experimental results is good. The temperature dependence of the diffusion coefficient yielded an activation energy of $156 \mathrm{~kJ} / \mathrm{mole}$ for SFC-2; this is within the range of values reported for several perovskite-structure oxides.

\section{ACKNOWLEDGMENTS}

Work at Argonne National Laboratory is supported by the U.S. Department of Energy, Pittsburgh Energy Technology Center, under Contract W-31-109-Eng-38.

\section{REFERENCES}

1. U. Balachandran et al., Am. Ceram. Soc. Bulletin, Vol. 74, No. 1, p. 71 (1995).

2. R. E. Kirk and D. F. Othmer, eds., Encyclopedia of Chemical Technology, 3rd Ed., Vol. 12. Wiley Interscience, New York, p. 952 (1980).

3. Y. Teraoka, H. M. Zang, S. Furukawa, and N. Yamazoe, Chem. Lett., p. 1743 (1985).

4. T. Nobunaga and N. Yamazoe, Chem. Lett., p. 503 (1988).

5. Y. Teraoka, T. Fukuda, N. Miura, and N. Yamazoe, J. Ceram. Soc. Jpn. Int. Ed., p. 523 (1989)

6. U. Balachandran, S. Morissette, J. Picciolo, J. Dusek, R. Poeppel, S. Pei, M. Kleefisch, R. Mieville, T. Kobylinski, and C. Udovich, Int. Gas Research Conf., Government Institutes, Inc., Rockville, MD, p. 565 (1992). 
7. H. J. M. Bouwmeester, H. W. Brinkman, R. H. E. van Doorn, H. Kruidhof, and A. J. Burggraaf, 3rd Intl. Conf. on Inorganic Membranes, ICIM, Worcester, MA. (July 10-14) 1994).

8. U. Balachandran et al., 3rd Int. Conf. on Inorganic Membranes, ICIM, July 10-14. Worecester, MA (1994).

9. T. M. Gür, A. Belzner, and R. A. Huggins, J. Membrane Sci., Vol. 75, p. 151 (1992).

10. B. A. van Hassel, T. Kawada, N. Sakai, H. Yokokawa, M. Dokiya, and J. M. Bouwmeester, Solid State Ionics, Vol. 66, p. 295 (1993).

11. H. Schmalzried, Solid State Reactions, Monographs in Modern Chemistry, Series Ed., H. F. Ebel, Verlag Chemie, Weinheim, Germany, p. 59 (1981).

12. C. Wagner, in International Committee of Electrochemical Thermodynamics and Kinetics, Proc. 7th Meeting, Lindau, Butterworths, London, 7, p. 361 (1957).

13. T. A. Ramanarayanan, S. Ling, and M. P. Anderson, in Proc. 1st Int. Symp. on Ionic and Mixed Conducting Ceramics, eds. T. A. Ramanarayanan and H. L. Tuller, High Temperature Materials Division, Vol. 91-12, The Electrochemical Society, Inc., Pennington, NJ, p. 110 (1981).

14. H. Schmalzried, in Reactivity of Solids (Elsevier Science Publishers, B. V., Amsterdam), 1. p. 117 (1986).

15. H. Deng, M. Zhou, and B. Abels, Solid State Ionics, Vol. 74, p. 75 (1994).

16. B. Ma, J. H. Park, C. U. Segre, and U. Balachandran, Mater. Res. Symp., Vol. 393, p. 49 (1995).

17. G. Eriksson, Acta Chem. Scand. 25, p. 2651 (1971).

18. G. Eriksson, Chemica Scripta 8, p. 100 (1975).

19. S. Carter, A. Selcuk, R. J. Chater, J. Kajda, J. A. Kilner, and B. C. H. Steele, Solid State Ionics, Vol. 53-56, p. 597 (1992).

20. K. Nisancioglu, and T. M. Gür, Solid State Ionics, Vol. 72, p. 199 (1994). 
Table I. Experimental and SOLGAS computations of partial oxidation of methane/argon mixture at $1165 \mathrm{~K}$

\begin{tabular}{cccc}
\hline Species & $\begin{array}{c}\text { Moles, } \\
\text { Calculated }\end{array}$ & $\begin{array}{c}\text { Moles, } \\
\text { Experimental }\end{array}$ & $\begin{array}{c}\text { Ratio, } \\
\text { Exp/Calc. }\end{array}$ \\
\hline $\mathrm{Ar}$ & 21.24 & 21.24 & 1.00 \\
$\mathrm{H}_{2}$ & 164.9 & 180.5 & 1.09 \\
$\mathrm{O}_{2}$ & $9.68 \times 10^{-20}$ & $\mathrm{NA}$ & - \\
$\mathrm{CH}_{4}$ & 8.608 & 7.615 & 0.88 \\
$\mathrm{CO}_{2}$ & 0.298 & 0.123 & 2.42 \\
$\mathrm{CO}$ & 78.33 & 78.93 & 1.01 \\
$\mathrm{H}_{2} \mathrm{O}$ & 0.346 & $\mathrm{NA}$ & - \\
\hline
\end{tabular}




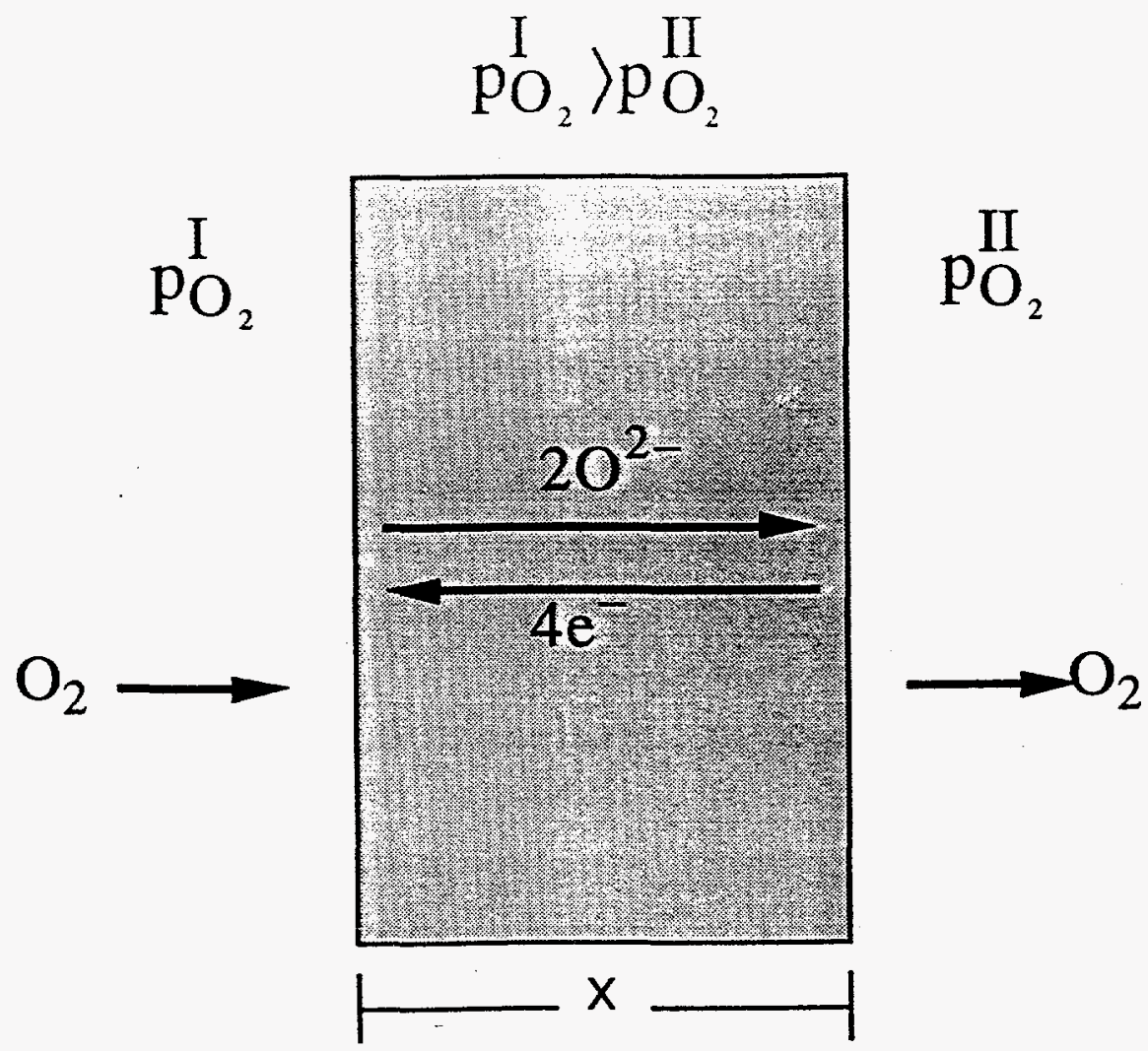

Fig. 1. Oxygen permeation through membrane wall thickness in oxygen potential gradient. 


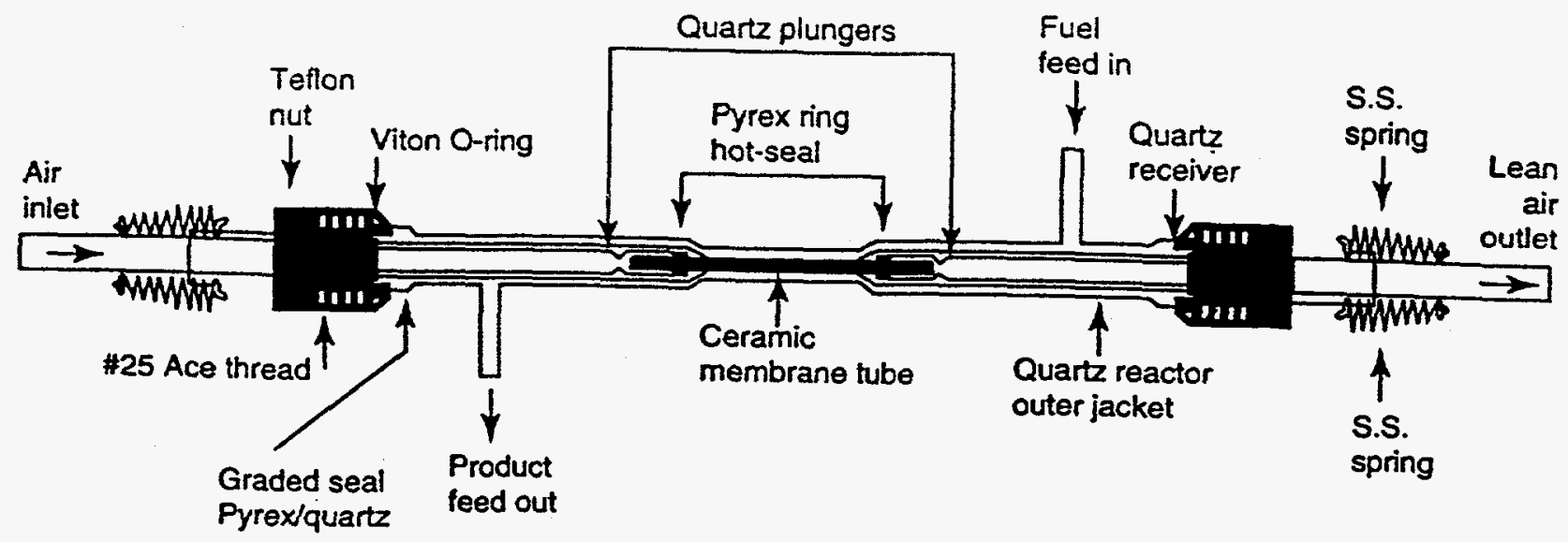

Fig. 2. Schematic diagram of methane conversion in reactor tube.

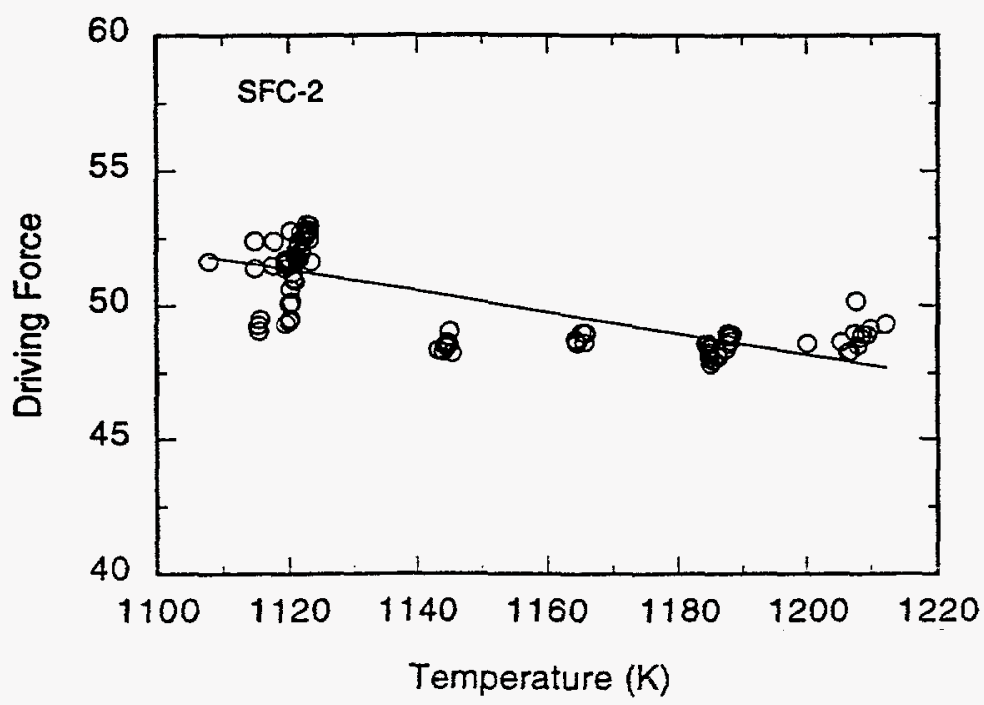

Fig. 3. Temperature dependence of driving force $\left(\ln \frac{\mathrm{pO}_{2}^{I}}{\mathrm{pO}_{2}^{I I}}\right)$ for oxygen transport. 


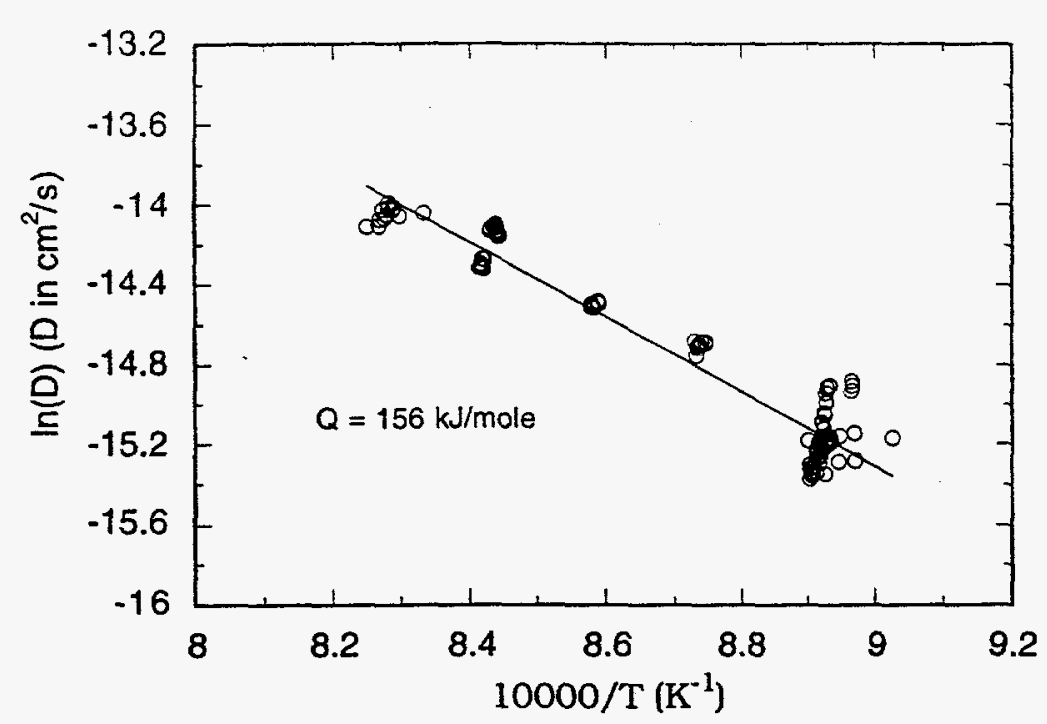

Fig. 4. Temperature dependence of oxygen diffusivity in SFC-2.

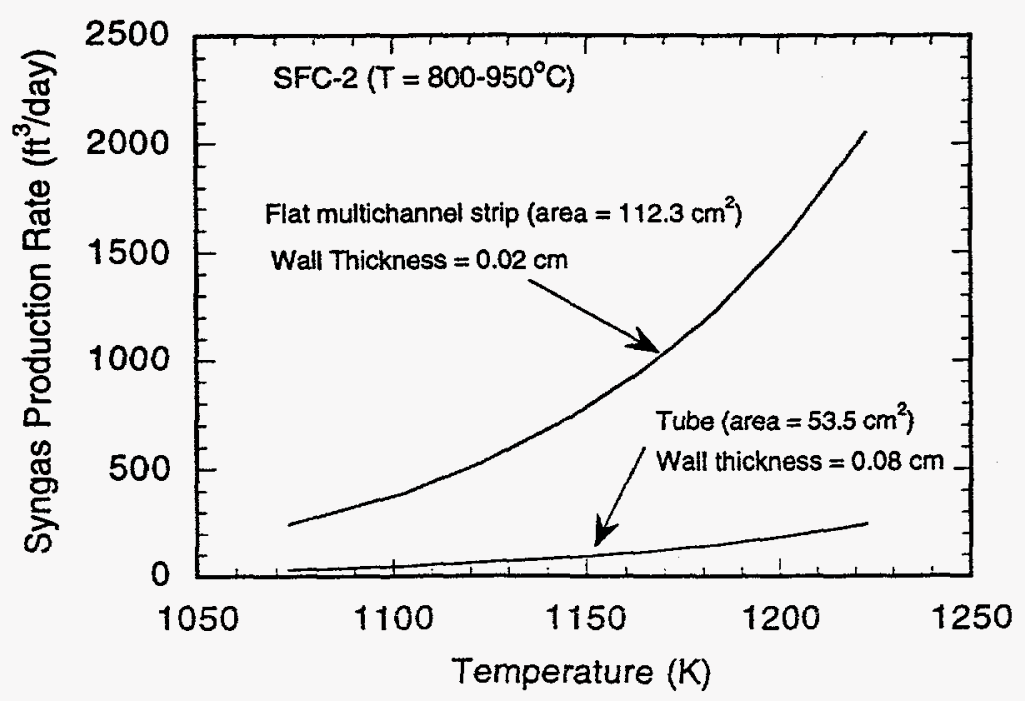

Fig. 5. Estimation of syngas production rate for two reactor geometries. 